\section{SURGICAL MISCELLANIES.} BY JOHN CLELAND, M.D., Professor of Anatomy and Physiology, Queen's College, Galway.

III.-Inguinal Hernia strangulated by an Artery. ON April 5th, I was asked to see a case of strangulated hernia. The patient was a robust man of middle age; the hemia was scrotal, of about the size of $a$ hen's egg, and seemingly direct; but it is proper to state that a truss had been worn on account of it for some years. The taxis made no impression on the size of the swelling, which was firm, and gave a dull sound on percussion; and, as symptoms of strangulation had existed for more than twelve hours, and vomiting had now set in, and the patient's expression was anxious, and the pulse small and wiry, I proceedcd to operate, with the assistance of Dr. Brereton, Demonstrator of Anatomy, and Dr. England, the practitioner attending the case.

The superficial fat, which was very thick, having been divided, and the sac of the hernia exposed by dissection, it appeared to me that the cause of strangulation was at the superficial inguinal ring, and I divided the aponeurosis of the external oblique muscle for about a quarter of an inch. As soon, however, as this was donc, a slight additional descent of intestine took place at the enlarged aperture, while the original hernia retained its dimensions, and was separated by a tight hour-glass constriction from the new bulging above. Thus, the whole cause of strangulation was seen to be situated at the constriction which lay before our eyes. On passing a finger down by the sides of this constriction, it was found that there was a structure like a string tightly grasping the intestine on the sides as well as in front. Feeling uncertain what was the exact state of matters, I deemed it expedient to push an aneurism-needle beneath this structure, and, in doing this, perforated the sac, when a considerable escape of sanious fluid took place, but without the effect of relicving strangulation. I had then an opportunity of cxamining at leisure the strangulating structure, and of observing that it was certainly an artery, quite free from thickened tissue, but stretched with a tightness that made circulation impossible. The vessel was tied in two places, and was divided between the ligatures slowly, an attempt being made to examine the section. This was so far successful that a slightly darker appearance of the internal, contrasting with the middle coat of the vessel, was seen; but, in attempting further examination, the inner of the two ligatures became loosened just as the section was completed, and both ends of the divided structure sprang back, and were completely lost from view in the depth of the wound. No hæmorrhage followed the giving way of the ligature; but this is not remarkable, seeing that it was the inner of the two. The strangulation was completely relieved, and it was considered unnecessary to open the sac further; the hernia was easily returned, but, on account of the distention of the abdomen, the width of the aperture, and the struggles of the patient, it was difficult to prevent its re-descent.

In the evening, the patient appeared considerably relieved. But, next morning, the patient's pinched appearance and a return of the wiry pulsc and the vomiting, indicated that there was something radically wrong, and the bandages were found loosened and the hernia re-descended. The wound was re-opened, and the neck of the sac, which on the previous day had been thin and uninflamed, was found thickened and tightly constricted. The sac was opened in the upper part, but was found adherent to the intestine below. The new strangulation was relieved by means of the probe-pointed bistoury, just sufficiently to allow the intestine to be returned on application of considerable pressure; and the thickening which had caused this second strangulation was sufficient to retain the intestine in the abdomen. The patient recovered.

I record this case, believing that we have in it an instance of an in. guinal hernia constricted by an obturator artery arising from the epigastric and arching upwards in its course, or by a common trunk of un. usual length, from which the obturator and epigastric arteries were given of nearer the middle line. There can be no doubt that the strangulating structure was an artery; but that the anatomy of the parts is obbeing is undeniable. The circumstance, however, of an inguinal hernia being strangulated by an artery ought to be noted.

\section{ON THE USE OF CARBOLIC ACID IN THE TREATMENT OF PRIMARY SYPHILIS.}

\author{
By HOLMES COOTE, EsQ.,
}

Surgeon to St. Bartholomew's Hospital, London.

I BEG to call attention to the treatment of syphilis in its primary forms by the local application of carbolic acid. This practice has been followed with success in several foreign stations, and particularly in one of H.M. ships stationed at the Pirxus Although I have no authority to mention the name of the surgeon of the vessel, I yet heard from good authority that he had reported favourably of the practice, and had oblained some satisfactory results.

My first trial was on patients in the female venereal ward. All surgeons know the trouble and difficulty sometimes experienced in the removal of mucous tubercles, whose growth sometimes appears to be stimulated into additional activity by the employment of the usual
caustics.

CASE I.-Emily K., aged $2 \mathrm{r}$, general servant, had a discharge from the vagina, with numerous mucous tubercles on the labia and inside of the thighs. On January 17 th, 1868, carbolic acid. lotion (gr. $v$ to the ounce of water) was ordered. On February 7 th, she was discharged, all the tubercles having disappcared. The period of treatment was three wecks. It was then determincd to employ a much stronger so.
lution.

CASE 11.- Jane P., agcel 19. This case was similar to the former; but the tubcrcles were morc numerous and larger. On January 21 st, a lotion composed of carbolic acid and water, equal parts, was ordered to be applied by means of a brush each day; and the ustal carbolic acid the tubercles hat constantly applied to the parts. On February 2nd, the tubercles had entirely disappeared. In this case, the period of
treatment was twelve days.

CASE III.- Catherine II., aged 20, had a discharge from the vagina, with a mass of mucous tubercles on the labia and upper part of the thighs, and around the anus. On January $24^{\text {th }}$, the strong lotion, consisting of equal parts of carbolic acid and water, was ordered to be painted on daily with a brush, as in the preceding case; the usual carbolic acid lotion to be constantly applied. On February 7 th, the tubcrcles had almost entirely disappeared. The patient was nearly wcll. In this case, the period of treatment was fourteen days.

In all these cases, the pain was inconsiderable; nor was there any necessity for the use of surgical instruments, such as scissors, etc.

I am engaged in trying the effect of carbolic acid, both pure and diluted with equal parts of water, in primary venereal sores of all kinds in both sexes, and will communicate the result at some futurc time.

\section{A SUBSTITUTE FOR THE LIGATURE.}

BY N. R. SMITH, M.D.,

Professor of Surgery in the University of Baltimore.*

I HAVE recently devised a little apparatus as a substitute for the ligature and acupressure in the ligation of arteries. It consists of a small silver tube, and a fine annealed iron wire passed double through the tube and projecting a loop at one extremity. The tube has a small double slit at one end. In applying it, the loop of wire is laid over the bleeding artery; the vessel is then seized with the forceps or tenaculum, and raised. The operator now, holding the tube with his fingers or forceps, seizes the free ends of the wire, and draws them steadily but firmly till the artery is tightly seized by the wire-loop. He now bends the clouble wire down into the fissure in the margin of the tube, and then gives it one turn around the end of the tube. Then he clips with the scissors the ends of the wire, leaving length cnough to be seized by the fingers in removing it.

When the ligature has accomplished its purpose, it is to be removed by seizing the tube with forccps, unwinding the wires, disengaging them from the slit, and then seizing them with pliers and steadily drawing the wire-loop through the canal of the tube, thus severing the artery as by a small icrisciur.

It may be removed from arteries of the fourth or fifth magnitude in six hours with safety. I have removed it from the femoral artery, after amputation of the thigh, on the second day. In a case in which $I$ ap. plied the apparatus to two arteries, after amputation of the breast, I found them disengaged on the second day, and on touching them they slipped away without the slightest resistance. 